\title{
Spectrum and prevalence of nodular thyroid diseases detected by ultrasonography in the Western Black Sea region of Turkey
}

\author{
Yusuf Aydin', Fahri Halit Besir², Melih Engin Erkan³, Omer Yazgan², Adem Gungor', \\ Elif Onder ${ }^{1}$, Hulya Coşkun ${ }^{1}$, Leyla Aydin ${ }^{4}$ \\ for the MELEN investigators
}

${ }^{1}$ Internal Medicine Department, ${ }^{2}$ Radiology Department, ${ }^{3}$ Nuclear Medicine, ${ }^{4}$ Chest Disease Department, Duzce University, Medical Faculty, Duzce, Turkey

\begin{abstract}
Objective: The aim of the study was to investigate thyroid diseases and the prevalence of goiter by ultrasonography (US) in a moderately iodine deficient area. Material-Methods: The MELEN Study is a prospective cohort study on the prevalence of thyroid diseases in Turkish adults. A total of 2233 subjects with a mean age of 50 (age range 18 to 92 ) were submitted to study. Thyroid US was performed and interpreted by the same experienced physician. Goiter prevalence was defined according to Gutekunst's criteria. Results: The most common thyroid disease was multinodular goiter (MNG) (42\%), followed by nodular goiter $(\mathrm{NG})(14.6 \%)$. The crude prevalence of nodular disease in the region was $56.6 \%$. In the study cohort, thyrotoxicosis $(\mathrm{TSH}<0.35 \mu \mathrm{IU} / \mathrm{ml}$ ) prevalence was $12 \%$ and subclinical and overt hypothyroidism (TSH $>4.5 \mu \mathrm{IU} / \mathrm{ml}$ ) prevalence was 6.5 $\%$. Conclusion: We found that thyrotoxicosis and nodular thyroidal diseases are more important public health issues in moderate iodine deficient geographical areas. We recommend the increased rates of US screening especially in the endemic regions in order to detect thyroidal nodules earlier.
\end{abstract}

Keywords: goiter, prevalence, thyroid nodule, ultrasonography

\section{Introduction}

Endemic goiter is an important and continuing health problem all over the world. It has been described as an enlargement of the thyroid tissue due to several causes. Endemic goiter describes thyroid hyperplasia, which exists in more than $5 \%$ of the people living in a particular region. Endemic goiter is a result of iodine deficiency or a goitrogenic substance $[1,2]$.

Received 20.02.2014 Accepted 03.04.2014

Med Ultrason

2014, Vol. 16, No 2, 100-106

Corresponding author: Fahri Halit BESİR, Assoc Prof

Düzce University, School of Medicine,

Department of Radiology

Konuralp-Duzce-Turkey, 81600

Phone: +90 380 5421390, Fax: +90 3805421302

E-mail: drfhbesir@gmail.com
The leading and the most common cause of endemic goiter is iodine deficiency. The Black sea region is a mountainous region that has long been known to suffer from moderate iodine deficiency and it is also a center of endemic goiter in Turkey [2-4].

Thyroid ultrasonography (US) has been used for early detection and qualitative evaluation of thyroid nodules in recent studies [3]. In Turkey, results of US thyroid volume examination have demonstrated that thyroid volume was higher in school age children in Ankara and in the Black Sea region than in European children [4]. However, a population based ultrasonographic prevalence examination in this region has not been conducted yet. Therefore, the aim of the present study was to investigate the epidemiology of goiter and ultrasonographic thyroid disorders using US in the western region of the Black Sea in Turkey. 


\section{Material and methods}

\section{Study population}

The MELEN Study is a prospectively designed survey on the prevalence of cardio metabolic risk factors and thyroid diseases in Turkish adults [5]. The name of the study comes from the geographic valley and rivers in north-east of Duzce, Turkey which has a population of 21,000 people. There is a town centre (Yigilca) and 37 villages. Health service of the region was supplied by six family physicians, each following up almost 2,500 adults. The study was conducted in May and June 2010 in the Social Health center located in the town center. Four hundred subjects from each family physician representatively stratified for sex, age and for rural-urban distribution were randomly assigned and invited by phone to participate in the study. A total of 2298 subjects with a mean age of 50 years (age range 18 to 92 ) were interviewed. There were 17 subjects ( 12 female and 5 male) that were under thyroid hormone regulation drugs and were excluded from study. Also, 48 participants who had refused to undergo thyroid US were excluded. Thyroid autoantibodies were not evaluated due to the high cost. The study protocol was approved by the Ethics Committee of Duzce University and every subject signed a consent form. Personal data were obtained by a questionnaire with face to face conversation. Also a history of nutritional habits (iodine intake, vegetable consumption), smoking habits and amount of alcohol consumption were all noted.

\section{Thyroid US measurements and definitions}

Thyroid US was performed and interpreted by the same experienced physician, using the same equipment with a $5-12-\mathrm{MHz}$ linear-array transducer (M Turbo, SonoSite Inc, Bothell, WA, USA). The subjects were examined in the supine position with hyper extended neck. Images were obtained in the transverse and longitudinal planes. The length, width, and depth of each lobe were measured, and the volume was calculated by the mean of the elliptical shape volume formula $(\pi / 6 \times$ length $\times$ width $\times$ depth $)$. Size of the thyroid lobes and characteristics of thyroid parenchyma and nodules dimensions and volumes were determined. In order to establish the total volume of the thyroid, estimated volumes of the right and left lobes were added [6]. Volume of the isthmus was not included in this calculation. Goiter prevalence was defined according to Gutekunst's criteria. Gutekunst reference values for adults $\left(>18 \mathrm{~cm}^{3}\right.$ in women and $>25 \mathrm{~cm}^{3}$ in men) were used [7,8]. US findings were classified as follows: Group 1- normal thyroid US (normal parenchyma, and volume); Group 2-hyperplasic thyroid gland (increased thyroid volume but in normal thyroid parenchyma appearance); Group 3- thyroiditislike (non-homogeneous thyroid parenchyma, grade 2-3 heterogeneity, without nodules); Group 4- nodular goiter (NG) (increased thyroid volume with only one nodule); Group 5- multinodular goiter (MNG) (increased thyroid volume with 2 or more that 2 nodules); Group 6- recurrent nodular goiter; Group 7- totally thyroidectomised (no thyroid gland after surgery); Group 8- others: hypoplasic (4 participants), atrophic thyroid gland (2 subjects), hemiagenis of thyroid gland (2 subjects), subtotal thyroid operation (3 participants). Nodules diameter $>5 \mathrm{~mm}$ was accepted as real nodular appearance. Fine needle biopsy is not recommended clinically for nodules smaller than $5 \mathrm{~mm}$. So, the nodules smaller than $5 \mathrm{~mm}$ were not evaluated with US and nodules diameter $>5 \mathrm{~mm}$ was accepted as real nodular appearance [9].

Biochemical and complete blood count analysis

Ten $\mathrm{mL}$ of blood were drawn from the antecubital vein of each subject by applying minimal tourniquet force. The first $2 \mathrm{~mL}$ of blood, which was used for the full blood count, was drawn into a vacutainer tube containing 0.04 $\mathrm{mL}$ of the $7.5 \% \mathrm{~K} 3$ salt of ethylene diamine tetraacetic acid (EDTA). The $8 \mathrm{~mL}$ of blood was drawn into a vacutainer tube without anticoagulant. These blood samples were allowed to clot for 20 minutes prior to centrifugation. The blood tubes were centrifuged for $10 \mathrm{~min}$ at 1500 $\mathrm{x} g$ and were processed within 30 minutes in place. Sera were aliquoted. Sera were shipped within a few hours on cooled gel packs at $2-5^{\circ} \mathrm{C}$ to the Duzce University central laboratory. Aliquots of the serum were kept in Eppendorf tubes frozen at $-80{ }^{\circ} \mathrm{C}$ until the final analyses.

Complete blood counts were made by CELL-DYN 3700 SL analyzer (Abbott Diagnostics, Chicago, USA). After an overnight fast, blood samples were collected from all the study subjects for the serum free thyroxin (fT4), thyroid stimulating hormone (TSH). Serum TSH and fT4 levels were evaluated using an Abbott Architect 2000 device with Chemiluminescence Microparticle Immunoassay (CMIA) method. Normal ranges in our laboratory are as follows: TSH $0.35-4.50 \mu \mathrm{IU} / \mathrm{ml}$, fT4 $0.70-1.48 \mathrm{pg} / \mathrm{ml}$. TSH over $4.50 \mu \mathrm{IU} / \mathrm{ml}$ with decreased fT4 was accepted as overt hypothyroidism, TSH over $4.50 \mu \mathrm{IU} / \mathrm{ml}$ with normal fT4 accepted as subclinical hypothyroidism, and TSH below $0.35 \mu \mathrm{IU} / \mathrm{ml}$ with increased fT4 accepted as overt (clinical) hyperthyroidism, TSH below $0.35 \mu \mathrm{IU} / \mathrm{ml}$ with normal fT4 accepted as subclinical hyperthyroidism.

\section{Statistical Analyses}

The Statistical Package for Social Sciences software (SPSS 15, Chicago, IL, USA) was used for analysis. Descriptive parameters were shown as mean \pm standard deviation or in percentages. Independent samples t-tests and Pearson's chi-square tests were used to analyze the 
Table I. Demographic characteristics and thyroid related features of the study population (2233 subjects)

\begin{tabular}{|c|c|c|}
\hline & Patients & P value \\
\hline Age (years) & $50 \pm 15$ & \\
\hline Female/Male & $1430 / 803$ & \\
\hline Body Mass index (BMI) & $29 \pm 7$ & \\
\hline Regular Alcohol user & $112(5 \%)$ & \\
\hline Active smoker & $386(17 \%)$ & \\
\hline Diabetes Mellitus History & $279(12.5 \%)$ & \\
\hline \multicolumn{3}{|l|}{$\begin{array}{l}\text { Salt Intake } \\
\quad \text { Without Iodine } \\
\text { With Iodine } \\
\text { Mean Thyroid Volume } \\
\left(\mathrm{cm}^{3}\right)\end{array}$} \\
\hline $\begin{array}{l}\text { Mean Thyroid Volume } \\
\left(\mathrm{cm}^{3}\right) \\
\\
\text { Female } \\
\text { Male }\end{array}$ & $\begin{array}{l}18.3 \pm 16.3 \\
19.5 \pm 14.5\end{array}$ & 0.095 \\
\hline $\begin{array}{l}\text { Goiter prevalence }(\mathrm{N}: 2175) \\
\text { Female }\left(\text { Volume }>18 \mathrm{~cm}^{3}\right) \\
\text { Male }\left(\text { Volume }>25 \mathrm{~cm}^{3}\right)\end{array}$ & $\begin{array}{l}665(31 \%) \\
482(35 \%) \\
183(23 \%)\end{array}$ & $<0.001$ \\
\hline $\begin{array}{c}\mathrm{TSH}(\text { mean) } \mu \mathrm{IU} / \mathrm{ml} \\
\mathrm{TSH}(\text { median) } \mu \mathrm{IU} / \mathrm{ml} \\
\text { Female } \\
\text { Male }\end{array}$ & $\begin{array}{c}1.94 \pm 4.56 \\
0.95 \text { (min: } 0.01 \max : 72.4) \\
2.1 \pm 5.1 \\
1.7 \pm 5.7\end{array}$ & 0.029 \\
\hline $\begin{array}{l}\text { Free T4 pg/ml. } \\
\qquad \begin{array}{l}\text { Female } \\
\text { Male }\end{array}\end{array}$ & $\begin{array}{l}1.13 \pm 0.19 \\
1.12 \pm 0.29 \\
1.15 \pm 0.18\end{array}$ & 0.001 \\
\hline $\begin{array}{c}\mathrm{TSH}(\mathrm{N}: 2112) \mu \mathrm{IU} / \mathrm{ml} \\
<0.35 \\
0.35-4.50 \\
>4.50\end{array}$ & $\begin{array}{l}275(12.9 \%) \\
1687(80 \%) \\
150(7.1 \%)\end{array}$ & \\
\hline
\end{tabular}

Results are shown as mean \pm standard deviation or in percentages $(\%)$ differences in means and proportions between groups. A $p$ value of $<0.05$ was considered significant.

\section{Results}

A total of 2298 subjects with a mean age of 50 (age range 18 to 92) constituted the main study cohort. Out of this, 2233 subjects ( 1430 women, 803 men, with a mean age of $50 \pm 15$ years) constituted the final cohort. It was constituted that this represented $10 \%$ of the population in the examined area. Demographic characteristics and thyroid related features of the study cohort are shown in table I.

After the exclusion of 58 participants who had undergone a total thyroidectomy procedure, 2175 subjects were analyzed for goiter prevalence according to Gutekunst's criteria. The prevalence of goiter showed a significant female predominance (35\% in women and $23 \%$ in men, $\mathrm{p}<0.001)$. The lowest frequency of goiter was observed in the 18 to 30 -year age group and the highest frequency was observed in those between 40-70 years. However, the mean thyroid volume was similar among female and male subjects. The rate of iodized salt use was $97 \%$. According to TSH values, thyrotoxicosis ( $\mathrm{TSH}<0.35 \mu \mathrm{IU} /$ $\mathrm{ml}$ ) rate was $12.9 \%$ and subclinical and overt hypothyroidism (TSH $>4.5 \mu \mathrm{IU} / \mathrm{ml}$ ) rate was $7.1 \%$. A relatively higher prevalence of thyrotoxicosis was detected possibly due to the higher frequency of MNG and NG

According to thyroid US examination the most common thyroid disease was MNG (42\%), followed by NG (14.6\%). Taking into account that 196 subjects had been operated possibly due to nodular/multinodular goiter, the crude prevalence of nodular thyroid disease in the region reached $65 \%$. The prevalence of normal thyroid gland was only $27.4 \%$. The operation rate in the cohort was $8.7 \%$.

Table II. Prevalence and characteristics of thyroid ultrasonographic pathologies

\begin{tabular}{|c|c|c|c|c|c|c|c|c|c|}
\hline & Group 1 & Group 2 & Group 3 & Group 4 & Group 5 & Group 6 & Group 7 & Group 8 & Total \\
\hline$(n / \%)$ & $\begin{array}{c}614 \\
(27.4)\end{array}$ & $\begin{array}{c}82 \\
(3.7)\end{array}$ & $\begin{array}{c}60 \\
(2.6)\end{array}$ & $\begin{array}{c}327 \\
(14.6)\end{array}$ & $\begin{array}{c}943 \\
(42.2)\end{array}$ & $\begin{array}{l}138 \\
(6.2)\end{array}$ & $\begin{array}{c}58 \\
(2.6)\end{array}$ & $\begin{array}{c}11 \\
(0.04)\end{array}$ & $\begin{array}{l}2233 \\
(100)\end{array}$ \\
\hline Female & 357 (24.9) & $39(27.3)$ & $50(3.5)$ & $205(14.3)$ & $602(42.1)$ & $118(8.2)$ & $52(3.6)$ & $9(0.06)$ & 1430 \\
\hline Male & $257(32)$ & $49(12.2)$ & $10(1.2)$ & $122(15.2)$ & $341(42.5)$ & $22(2.7)$ & $6(0.7)$ & $2(0.02)$ & 803 \\
\hline Age & $41 \pm 15$ & $47 \pm 13$ & $49 \pm 15$ & $50 \pm 14$ & $55 \pm 13$ & $53 \pm 12$ & $55 \pm 10$ & $47 \pm 16$ & - \\
\hline $\begin{array}{l}\text { TSH }<0.35 \\
\mu \mathrm{IU} / \mathrm{ml}\end{array}$ & $34(12.5)$ & $9(3.3)$ & $4(1.2)$ & $36(13.5)$ & $167(62.5)$ & $5(1.5)$ & $9(3.3)$ & $1(0.01)$ & 267 \\
\hline $\begin{array}{l}\text { TSH:0.35- } \\
4.5 \mu I U / m l\end{array}$ & $514(31)$ & $68(4.1)$ & $40(2.4)$ & $245(15)$ & $673(41.1)$ & $75(4.5)$ & $20(1.3)$ & $5(0.02)$ & 1639 \\
\hline $\begin{array}{l}\text { TSH }>4.5 \\
\mu \mathrm{IU} / \mathrm{ml}\end{array}$ & $16(11)$ & $12(8.3)$ & $14(9.7)$ & $29(20)$ & $46(30.5)$ & $26(18)$ & $2(1.5)$ & $5(0.02)$ & 145 \\
\hline
\end{tabular}

Results are shown as mean \pm standard deviation or in percentages (\%) 
Table III. Mean thyroid gland volumes ( $\mathrm{cm} 3$ ) according to the US diagnosis and gender difference

\begin{tabular}{lccccccc}
\hline & $\begin{array}{c}\text { Group 1 } \\
\text { n:614 }\end{array}$ & $\begin{array}{c}\text { Group 2 } \\
\text { n:82 }\end{array}$ & $\begin{array}{c}\text { Group 3 } \\
\text { n:60 }\end{array}$ & $\begin{array}{c}\text { Group 4 } \\
\text { n:327 }\end{array}$ & $\begin{array}{c}\text { Group 5 } \\
\text { n:943 }\end{array}$ & $\begin{array}{c}\text { Group 6 } \\
\text { n:138 }\end{array}$ & $\begin{array}{c}\text { Group 8 } \\
\text { n:11 }\end{array}$ \\
\hline Mean Volume & $11.9 \pm 7.09$ & $21.8 \pm 11.9$ & $11.0 \pm 8.4$ & $18.6 \pm 12.9$ & $25.1 \pm 18.7$ & $7.3 \pm 8.2$ & $9.7 \pm 7.3$ \\
Female & $11.1 \pm 6.8$ & $20.6 \pm 8.9$ & $10.9 \pm 8.4$ & $18.7 \pm 14.0$ & $25.2 \pm 19.4$ & $7.2 \pm 8.3$ & $9.2 \pm 6.4$ \\
Male & $13.3 \pm 7.3$ & $23.1 \pm 14.1$ & $12.0 \pm 8.7$ & $18.6 \pm 10.9$ & $24.9 \pm 17.5$ & $8.2 \pm 7.4$ & $10.7 \pm 7.4$ \\
\hline
\end{tabular}

Results are shown as mean \pm standard deviation

Table IV. Demographic parameter of patients with (+) and without (-) goiter

\begin{tabular}{lccc}
\hline & GOITER (+) & GOITER (-) & P \\
\hline Normal USG & $63(9.5)$ & $551(36.5)$ & $<0.001$ \\
Hiperplasia & $38(5.7)$ & $44(2.9)$ & $<0.001$ \\
Thyroiditis-like & $7(1)$ & $53(3.5)$ & $<0.001$ \\
Nodular Goiter & $101(15.2)$ & $226(15)$ & NS \\
M. Nodular Goiter & $445(66.9)$ & $495(32.8)$ & $<0.001$ \\
Recurrent N. Goiter & $10(1.5)$ & $128(8.5)$ & $<0.001$ \\
Other & $9(1.4)$ & $2(0.01)$ & $<0.001$ \\
Total & 665 & 1510 & - \\
Age & $55 \pm 14$ & $47 \pm 15$ & $<0.001$ \\
Active smoker & $84(12.6)$ & $296(20)$ & $<0.0001$ \\
Alcohol & $21(3)$ & $90(6)$ & 0.006 \\
Iodine salt $(+)$ & $639(97)$ & $1446(97)$ & 0.788 \\
Vegetable consumtion $(+)$ & $473(72)$ & $1136(76)$ & 0.036 \\
Mean thyroid volume $(\mathrm{cm} 3)$ & $35.73 \pm 17.93$ & $11.24 \pm 5.22$ & $<0.001$ \\
TSH ( $\mu$ IU $/ \mathrm{ml})$ & $0.802 \pm 0.980$ & $2.03 \pm 3.58$ & $<0.001$ \\
Free T4 (pg/ml) & $1.17 \pm 0.21$ & $1.11 \pm 0.18$ & $<0.001$ \\
Birth number & $5.24 \pm 2.82$ & $3.96 \pm 2.80$ & $<0.001$ \\
Abortus number & $1.0 \pm 1.34$ & $0.77 \pm 1.12$ & 0.001 \\
\hline Re & & &
\end{tabular}

Results are shown as mean \pm standard deviation or in percentages $(\%)$

Table V. Overt and subclinical hypothyroidism and thyrotoxicosis

\begin{tabular}{lccc}
\hline & Female & Male & p \\
\hline Subclinical hypothyroidism & $63(4.4)$ & $23(3)$ & NS \\
Overt hypothyroidism & $19(1.4)$ & $14(1.7)$ & NS \\
Subclinical hyperthyroidism & $160(11.4)$ & $87(11)$ & NS \\
Over hyperthyroidism & $7(0.5)$ & $5(0.6)$ & NS \\
\hline
\end{tabular}

Results are shown in percentages (\%). NS -Non-Significant

However, two thirds of them had recurrent nodular thyroid disease making up $6.2 \%$ of the whole population. The patients who had undergone total thyroidectomy procedure did not show any recurrence. Gender and functional variables of the patients according to thyroid US examination are shown in table II. Mean thyroid gland volumes according to the diagnosis and gender difference were shown in table III. The comparison of patients with and without goiter is shown in table IV. Overt and subclinical hypothyroidism and hyperthyroidism are shown in table $\mathrm{V}$. 
Elevated serum TSH was found in 145 (6.5\%) subjects. In these participants, the prevalence of subclinical and overt hypothyroidism was similar both in women and men ( $p>0.05)$. Subclinical hypothyroidism was seen more than overt hypothyroidism.

Suppressed TSH levels $(<0.35 \mu \mathrm{IU} / \mathrm{ml})$ were found in $12 \%$ (267) of the subjects. Also, people with $\mathrm{TSH}<0.1 \mu \mathrm{IU} / \mathrm{ml}$ represented $2.8 \%$ of the subjects. The prevalence of subclinical and overt thyrotoxicosis was similar in women and men $(\mathrm{p}>0.05)$. Overt thyrotoxicosis was detected only in $12(0.57 \%)$ subjects. Thyrotoxicosis were detected more frequently in participants with $\mathrm{MNG}+\mathrm{NG}+$ recurrent $\mathrm{NG}$ than participants with normal thyroid+hyperplastic thyroid gland+thyroiditis-like findings on US examination $(14.8 \% \& 6.2 \%)(\mathrm{p}<0.001)$. The overall prevalence of TSH alterations, either elevated or suppressed, was $18.2 \%$.

\section{Discussion}

To our knowledge, this is the largest epidemiological survey screening goiter prevalence by using US in adults for the first time after 12 years of a mandatory salt iodinization program in Turkey.

The overall goiter prevalence by US was $31 \%$. Most prominent thyroid abnormalities determined by US was MNG and NG. The crude prevalence of nodular thyroid disease (MNG or NG) in the region reached up to $56.6 \%$. Also the overall prevalence of TSH alterations, either elevated or suppressed, was $18.2 \%$. Prevalence of goiter which determined by US was $35 \%$ in females and $23 \%$ in males. Thyroid volume, degree of goiter, and frequency and total number of nodules were all found according to increased age. The prevalence of goiter is as high as the other adult populations in other iodine-deficient areas, being more prevalent in females [10,11]. Colak et al reported that goiter was found by palpation in $54 \%$ of the males and $33 \%$ of the females (averagely $45.4 \%$ for both sexes) [12]. Among the subjects, $24.6 \%$ of females and $21.6 \%$ of males $(22.9 \%$ of all subjects) were found to have goiter by US according to the criteria established by Gutekunts et al $[7,8]$. Cetin et al reported that total goiter prevalence was $30.4 \%$ with palpation and $26 \%$ with US [13]. In the Colak et al study, the goiter prevalence by US was $14.2 \%$ for the urban and $36.2 \%$ for the rural areas [12]. In the present study, goiter prevalence was higher compared to the aforementioned studies. In our study, US examination was used to detect the thyroid diseases being a more precise method to determine thyroid volume and the method has been recommended as the standard criterion in epidemiological surveys $[14,15]$. In our findings, goiter and nodular thyroid disease were not decreased at this time period. In fact, the incidence and prevalence of thyroid nodules has been increased in recent decades.

In our study, we detected that thyroid volumes of men were higher than females with normal US findings (13.3 $\mathrm{ml}$ vs. $11.1 \mathrm{ml}$ ). But there was no volume difference between genders in overall US results (male: $19.5 \mathrm{ml}$, female: $18.3 \mathrm{ml}$ ). There are controversial results regarding the relation between gender and thyroid volume. Bayram et al reported that thyroid volumes in females detected with US were higher than males in students and in adults [16]. Similarly, Hintze et al reported that median thyroid volumes were $19.2 \mathrm{ml}$ in women and $16.6 \mathrm{ml}$ in men [17]. In our US result, thyroid volumes were increased in both sexes, but there were no gender differences.

The recent technological development of US has facilitated the early detection and qualitative evaluation of thyroid gland. The use of US is also beneficial to differentiate thyroid nodules and non-nodular thyroidal diseases (chronic thyroiditis, Graves and diffuse goiter) [3]. Recent epidemiologic studies showed that prevalence of asymptomatic thyroid nodules in the healthy population are not infrequent. Most of the subjects were not aware of their illnesses. Guth et al reported that there is a huge prevalence of thyroid nodules $(68 \%)$ detected by US evaluation [18]. In our US examination NG, MNG and recurrent NG prevalence were $14.6 \%, 42.2 \%$ and $6.2 \%$, respectively. In addition with operated cases (probably operated due to nodular goiter), prevalence of nodular thyroidal diseases increased to $65 \%$. These results were obtained after 12 years of routine iodine supplementation. Goldyreva et al reported that nodules were found in one out of five subjects. They also emphasized that nodular thyroidal diseases were significantly more frequent in women than in men as in our study [19]. In another recent study, Zhank et al reported that prevalence of thyroid US abnormalities ranged from $30.5 \%$ to $42.3 \%$ in the study population [20]. We found a substantially higher prevalence of thyroid nodules than expected considering the data of the previous studies. This is due to the examination made by US, allowing the detection of small thyroid nodules.

Prevalence of suppressed TSH values was similarly higher than the elevated TSH in both males and females. Erdogan et al reported that geriatric populations have $1.55 \%$ overt hypothyroidism, $2.65 \%$ subclinical hypothyroidism, $3.75 \%$ overt thyrotoxicosis and $6.18 \%$ subclinical thyrotoxicosis [21]. In another large study -the Pescopagano survey from Italy- the prevalence of hyperthyroidism and overt hypothyroidism were $0.2 \%$ and $3.8 \%$, respectively. And the prevalence of present or past hyperthyroidism was $2.9 \%$ [22]. We detected an extremely high prevalence of thyrotoxicosis $(12.4 \%)$. But, 
overt thyrotoxicosis clinics were very rare $(0.57 \%)$. In contrast to the mentioned Italian study, thyrotoxicosis was abundantly high in our study population. The prevalence of subclinical and overt hypothyroidism was 5.7\%. We did not include patients on L-thyroxine, methimazole and propythiouracyl supplementation during our study. Similarly, Ozbakir et al found that $12.6 \%$ subjects had either elevated $(6.5 \%)$ or suppressed $(6.1 \%)$ TSH levels. They also reported that overt hypothyroidism and clinical thyrotoxicosis were very low as in our survey [23]. In our study, the overall thyrotoxicosis was twice as high as the patients suffering from overt or subclinical hypothyroidism. Prevalence of thyrotoxicosis $(\mathrm{TSH}<0.35)$ was $62.5 \%$ in MNG and $13.5 \%$ in NG subjects. Also iodinated salt consumption was $97 \%$ in this area. So we thought that those two parameters affect the high prevalence in our study. This region has a high prevalence of thyroid nodularity and after iodine intake, those nodules became active nodules resulting in thyroxicosis.

Although the mean thyroid volume of active smokers was lower than past and non smokers, no effects of smoking habits on thyroid nodularity and goiter was detected [24].

There are some limitations to our study. Urinary iodine output and anti-thyroid antibodies values were not measured due to their high cost for a large population investigation. But Simsek et al reported that median urinary iodine excretion in newborns $(85 \mu \mathrm{g} / \mathrm{L})$ was significantly higher than their mothers $(40 \mu \mathrm{g} / \mathrm{L})$ in this region [24]. Furthermore iodinated salt consumption does not necessarily mean adequate iodine ingestion. But we could not analyze salt samples iodine content. Also we did not evaluate the thyroidal cancer prevalence in that population screening program due to the cost. So we did not give any information regarding malignancy prevalence of that region. Because our study was designated for adults, it did not give any information about the school age population.

In the present survey in our specific region of Turkey (Western Black Sea), we detected a high prevalence of goiter, thyroid nodularity, and functional autonomy increasing with age. We concluded that thyrotoxicosis and nodular thyroidal diseases are more important public health issues in moderate iodine deficient geographical areas. We recommend the increased rates of US screening especially in the endemic regions to detect the thyroidal nodules earlier.

Acknowledgement and finacial disclosure: This work was supported by the Duzce University Scientific Research Programme.

Conflict of Interest: There is no conflict of interest.

\section{References}

1. Zimmermann MB, Jooste PL, Pandav CS. Iodine-deficiency disorders. Lancet 2008; 372: 1251-1262.

2. Erdoğan G, Erdogan MF, Emral R, et al. Iodine status and goiter prevalence in Turkey before mandatory iodization. $\mathrm{J}$ Endocrinol Invest 2002; 25: 224-228.

3. Ito Y, Amino N, Miyauchi A. Thyroid ultrasonography. World J Surg 2010; 34: 1171-1180.

4. Erdoğan G, Erdoğan MF, Delange F, Sav H, Güllü S, Kamel N. Moderate to severe iodine deficiency in three endemic goitre areas from the Black Sea region and the capital of Turkey. Eur J Epidemiol 2000; 16: 1131-1134.

5. Aydin Y, Ozhan H, Albayrak S, et al. MELEN Study: Rationale, Methodology and Basic Results. Eur J Gen Med 2011; 8: 308-313.

6. Bayram F, Beyazyildiz A, Gökçe C, et al. The prevalence of iodine deficiency, serum thyroglobulin, anti-thyroglobulin and thyroid peroxidase antibody levels in the urban areas of Kayseri, Central Anatolia. Exp Clin Endocrinol Diabetes 2009; 117: 64-68.

7. Gutekunst R, Smolarek H, Hasenpusch U, et al. Goiter epidemiology: thyroid volume, iodine excretion, thyroglobulin and thyrotropin in Germany and Sweden. Acta Endocrinol (Copenh) 1986; $112: 494-501$.

8. Gutekunst R \& Martin-Teichert H. Requirements for goiter surveys and the determination of thyroid size. In: Iodine Deficiency in Europe. A Continuing Concern. Delange F, Dunn JT, Glinoer D. Eds. New York: Plenum Press 1993: 109-118.

9. Cappelli C, Castellano M, Pirola I, et al. The predictive value of ultrasound findings in the management of thyroid nodules. QJM 2007; 100: 29-35.

10. Gaitan E, Dunn JT. Epidemiology of iodine deficiency. Trends Endocrinol Metab 1992; 3: 170-175.

11. Vanderpump MP, Tunbridge WM, French JM, et al. The incidence of thyroid disorders in the community: a twentyyear follow-up of the Whickham Survey. Clin Endocrinol (Oxf) 1995; 43: 55-68.

12. Çolak R, Özkan Y, Keçeci M, et al. The Prevalence of endemic goiter in Keban county in Elazig city and evalution of iodine levels. Turk J Endocrinol Metab 2004; 1: 9-14.

13. Cetin H, Kisioglu AN, Gursoy A, Bilaloglu E, Ayata A. Iodine deficiency and goiter prevalence in Turkey after mandatory iodization. J Endocrinol Invest 2006; 29: 714-718

14. Berghout A, Wiersinga WM, Smits NJ, Touber JL. Determinants of thyroid volume as measured by ultrasonography in healthy adults in a non-iodine deficient area. Clin Endocrinol (Oxf) 1987; 26: 273-280.

15. Aydin LY, Aydin Y, Besir FH, et al. Effect of smoking intensity on thyroid volume, thyroid nodularity and thyroid function: the Melen study. Minerva Endocrinol 2011; 36: 273-280.

16. Bayram F, Borazan B, Torun E, et al. The prevelance of endemic goiter and iodine deficiency and evaluation of thyroid functions in an area of central Anatolia. Turk J Endocrinol Metab 2003; 7: 37-43. 
17. Hintze VG, Windeler J, Baumert J, Stein H, Köbberling J. Thyroid volume and goitre prevalence in the elderly as determined by ultrasound and their relationships to laboratory indices. Acta Endocrinol (Copenh) 1991; 124: 12-18.

18. Guth S, Theune U, Aberle J, Galach A, Bamberger CM. Very high prevalence of thyroid nodules detected by high frequency $(13 \mathrm{MHz})$ ultrasound examination. Eur J Clin Invest 2009; 39: 699-706.

19. Goldyreva TP, Tereshchenko IV, Rakhmanova LV. Thyroid gland alterations in Perm region residents as observed by means of ultrasonography. Klin Med (Mosk) 2006; 84: 52-56.

20. Zhang YK, Liu XG, Zhu WY, et al. Iodine Intake and Prevalence of Thyroid Disorders in Different Populations of Zhoushan, China. Acta Endo (Buc) 2011; 7: 345-355.

21. Erdogan MF, Atlı T, Ekinci C, Genc Y, Gokmen H, Erdogan G. Spectrum and prevelance of thyroid disorders in the el- derly living in an iodine deficient community. Turk J Geriatr 2002; 5: 9-53.

22. Aghini-Lombardi F, Antonangeli L, Martino E, et al. The spectrum of thyroidal disorders in an iodine deficient community: The Pescopagano Survey. J Clin Endocrinol Metab 1999; 84: 561-566.

23. Ozbakır O, Ogukan A, Kelestimur F. The prevalence of thyroid dysfunction among elderly subjects in an endemic goiter area of Central Anatolia. Endocr J 1999; 42: 713716.

24. Simsek E, Karabay M, Safak A, Kocabay K. Congenital hypothyroidism and iodine status in Turkey: A comparison between the data obtained from an epidemiological study in school aged children and neonatal screening for congenital hypothyroidism in Turkey. Pediatr Endocrinol Rev 2003; 1 Suppl 2: 155-161. 